\title{
Overexpression of microRNA-21 strengthens stem cell-like characteristics in a hepatocellular carcinoma cell line
}

\author{
Jinghang Jiang ${ }^{1,2+}$, Peipei Yang ${ }^{2 \dagger}$, Zhe Guo ${ }^{3+}$, Rirong Yang ${ }^{4}$, Haojie Yang ${ }^{5}$, Fuquan Yang ${ }^{1}$, Lequn Li $^{1}$
} and Bangde Xiang ${ }^{1 *}$

\begin{abstract}
Background: Liver cancer stem cells (LCSCs) have been shown to express higher levels of microRNA-21 (miR-21). Here, we examine the possible contributions of miR-21 to the phenotype of LCSCs in culture and in xenograft tumors in nude mice.

Methods: The hepatocellular carcinoma cell line MHCC-97H was stably transformed with a retroviral vector to establish cells overexpressing miR-21, while a cell line transformed with empty vector served as a negative control. RT-PCR and Western blotting were used to evaluate the effects of miR-21 overexpression on the expression of various LCSC markers, a Transwell assay was used to assess the effects on cell migration and invasion, and a spheroid formation assay was used to examine the effects on clonogenesis. The effects of miR-21 overexpression were also examined in tumors in nude mice.

Results: An MHCC-97H cell line was constructed that stably overexpresses miR-21 at 7.78 \pm 1.51 -fold higher levels than the negative control cell line. Expression of the LCSC markers CD13, Ep-CAM, CD90, and OCT4 was significantly higher in the miR-21-overexpressing cell line than in the negative control at both mRNA and protein levels. The overexpressing cell line formed larger, tighter, and more numerous spheroids. Overexpression of miR-21 was associated with greater cell migration and invasion. Tumors of overexpressing cells in nude mice had a significantly larger mean volume after 34 days of growth $\left(773.62 \pm 163.46 \mathrm{~mm}^{3}\right)$ than tumors of negative control cells $\left(502.79 \pm 33.94 \mathrm{~mm}^{3}, p=0.048\right)$, as well as greater mean weight $(0.422 \pm 0.019$ vs. $0.346 \pm 0.006 \mathrm{~g}, p=0.003)$.
\end{abstract}

Conclusions: Overexpression of miR-21 strengthens the phenotype of LCSCs, facilitating invasion, migration, and tumorigenesis in hepatocellular carcinoma.

Keywords: Hepatocellular carcinoma, Liver cancer stem cells, microRNA-21, Cancer stem cell, Retroviral vector

\section{Background}

Hepatocellular carcinoma (HCC) is one of the most common malignant tumors and a leading cause of cancerrelated deaths worldwide [1], making it a major health burden [2]. Challenges in early HCC diagnosis mean that most cases are detected too late to be curable. Surgical resection remains the preferred treatment $[3,4]$, but postoperative recurrence is high [5]. Therefore, understanding how HCC

\footnotetext{
* Correspondence: 474522490@qq.com

${ }^{\dagger}$ Equal contributors

'Department of Hepatobiliary Surgery, Tumor Hospital of Guangxi Medical University, Nanning 530021, Guangxi Zhuang Autonomous Region, China Full list of author information is available at the end of the article
}

recurs may allow the design of treatments or interventions to reduce it.

Cancer stem cells (CSCs), also referred to as "side populations" because they are low-abundance subpopulations in tumors, can initiate and sustain cell migration, invasion, and treatment resistance. CSCs are responsible for poor clinical outcome in tumor recurrence and metastasis $[6,7]$. The malignancy of a tumor correlates directly with the proportion of CSCs that it contains [8]. CSCs are not sensitive to radio- or chemotherapy $[9,10]$, so they can evade treatment and survive to cause recurrence. Liver cancer stem cells (LCSCs), like other CSCs, are sub-populations of tumor cells capable of unlimited proliferation, self-renewal, 
and differentiation [11, 12]. According to a hypothesis advocated by many investigators [13], the chief culprit behind HCC recurrence is LCSCs $[6,7,13]$. Inhibiting LCSC proliferation and differentiation or even eradicating LCSCs entirely may prove critical for reducing $\mathrm{HCC}$ recurrence after hepatectomy $[14,15]$.

To move closer to this objective, researchers have developed methods to isolate LCSCs from HCC tumor tissue and HCC cell lines such as MHCC-97H. Researchers have screened for microRNAs (miRNAs) differentially expressed between LCSCs and HCC cell lines. In many cancers including HCC, miRNAs function as tumor suppressor genes and as oncogenes to modulate tumor cell proliferation, apoptosis, differentiation, and cell cycling [16]. In addition, miRNAs regulate self-renewal and multi-differentiation to determine stem cell fates [17-19]. In LCSCs, down- and upregulation of certain miRNAs influence LCSC characteristics such as clonogenicity and cell proliferation [19].

Recent studies have shown that microRNA-21 (miR21 ) is expressed at higher levels in various CSCs than in the corresponding bulk tumor cells and that it influences CSC behavior [20]. Inhibiting miR-21 expression increases sensitivity to chemotherapy and inhibits colonyforming ability. LCSCs, like other CSCs, have been shown to express higher levels of miR-21 than bulk HCC cells [21], and studies in which LCSCs were transfected with an miR-21 mimic or inhibitor suggest that miR-21 drives HCC recurrence and metastasis [22]. These studies were performed on isolated LCSCs, leaving open the question of whether overexpression of miR-21 strengthens stem cell-like characteristics in a hepatocellular carcinoma cell line, which may provide an excellent in vitro system for studying processes that occur in postoperative $\mathrm{HCC}$ patients.

Therefore, in the present study, we generated an MHCC-97H cell line stably transfected with a retroviral vector encoding miR-21. We then analyzed in vitro the effects of constitutive miR-21 overexpression on the expression of various LCSC markers (CD13, Ep-CAM, CD90, OCT4) as well as on several LCSC functional characteristics (spheroid formation, invasion, migration). The cell surface markers CD13, Ep-CAM, and CD90 are often used to enrich for LCSCs [23-26], while OCT4 is a transcription factor essential for pluripotency and selfrenewal of embryonic stem cells [27-29]. To complement these in vitro studies, we examined the effects of miRNA-21 overexpression on tumorigenicity in nude mice.

\section{Methods}

\section{Cell culture}

MHCC-97H and HEK $293 \mathrm{~T}$ cells were obtained from the Liver Cancer Institute of Zhongshan Hospital, Fudan University (Shanghai, China) and cultured in Dulbecco's modified Eagle's medium (DMEM; Gibco, USA) supplemented with $10 \%$ fetal bovine serum (FBS; Gibco, USA), 100 units $/ \mathrm{ml}$ penicillin, and $100 \mathrm{mg} / \mathrm{ml}$ streptomycin. Cultures were incubated at $37{ }^{\circ} \mathrm{C}$ in a humidified atmosphere containing $5 \% \mathrm{CO}_{2}$.

\section{Plasmid constructs}

We cloned the miR-21 gene from 7702 liver cell genomic DNA (kindly provided by the Department of Immunology, Guangxi Medical University) using the following primers, which we designed using the Primer 5.0 software (Premier Biosoft International, USA): BamH1 forward primer, 5'-CGCGGATCCTTCTT GCCGTTCTGTAAGTGTT-3'; and SalI reverse primer, 5'-AGACGTCGAC TTCAAAACCCACAATGCAGCT TAG-3'. The primers were used in a polymerase chain reaction (PCR) to amplify a 589-bp product, which was cleaved with BamH1 and Sal1 and ligated into the appropriate cloning sites of the pBABE-puro retroviral vector (Cell Biolabs, USA). The resulting construct was named pBABE-puro-pre-miR-21.

\section{Retroviral particle production}

HEK 293 T cells were plated in six-well plates and maintained for $24 \mathrm{~h}$ in DMEM with $10 \%$ FBS. When cells were 60-70 \% confluent, they were transfected with $1 \mu \mathrm{g}$ of packaging plasmid PIK [30, 31] (kindly provided by the Department of Immunology, Guangxi Medical University), empty pBABE-puro vector, or pBABE-puro-premiR-21 using Lipofectamine 2000 (Invitrogen, USA) in OPTI-MEM I medium (Invitrogen) according to the manufacturer's instructions. After the 5-h incubation, the medium was replaced with DMEM containing $10 \%$ FBS without antibiotics. Cells were incubated for another $48 \mathrm{~h}$, and the medium containing retroviral particles was harvested, filtered through a $0.22-\mu \mathrm{m}$ filter (Corning, USA) into a Falcon tube, and stored at $-80{ }^{\circ} \mathrm{C}$.

\section{Stable cell line construction}

MHCC-97H cells were seeded into six-well plates and allowed to grow to $70-80 \%$ confluence. Then, the cells were infected with retroviral particles lacking miR-21 (negative control) or containing miR-21 in the presence of polybrene ( $8 \mu \mathrm{g} / \mathrm{ml}$, Sigma-Aldrich, USA) and incubated for $24 \mathrm{~h}$ at $37^{\circ} \mathrm{C}$. The culture medium enriched in retroviral particles was harvested and used to infect fresh plates of $70-80 \%$ confluent MHCC-97H cells, which were incubated for another $24 \mathrm{~h}$. The medium was replaced with DMEM containing $10 \%$ FBS and $1 \mu \mathrm{g} / \mathrm{ml}$ puromycin (Sigma) without other antibiotics, and cultures were incubated for 2 weeks. Medium was replaced every 3 days. Finally, the medium was replaced with DMEM containing $10 \%$ FBS, 100 units $/ \mathrm{ml}$ penicillin, $100 \mathrm{mg} / \mathrm{ml}$ streptomycin, and $500 \mathrm{ng} / \mathrm{ml}$ puromycin, 
and cultures were incubated for 2 months. The medium was replaced every 3 days.

\section{Quantitative real-time reverse transcription-PCR (RT-PCR)} to measure expression of miR-21 and CSC marker genes

Total RNA was extracted from cells using Trizol (Invitrogen) according to the manufacturer's protocol. Primers for reverse transcription were the following: miR-21, 5' -CTCAACTGGTGTCGTGGAGTCGGCAA TTCAGTTGAGTCAACAT-3'; and U6, 5'-CTCGCTT CGGCAGCACA-3'. The reverse transcription reaction was carried out at $4{ }^{\circ} \mathrm{C}$ for $20 \mathrm{~min}, 16{ }^{\circ} \mathrm{C}$ for $30 \mathrm{~min}$, $42{ }^{\circ} \mathrm{C}$ for $30 \mathrm{~min}$, and $85^{\circ} \mathrm{C}$ for $5 \mathrm{~s}$, followed by a hold at $4{ }^{\circ} \mathrm{C}$.

Reverse transcription of CSC marker genes was carried out using the PrimeScript ${ }^{\circ}$ RT Kit (Takara Biotechnology, Dalian, China), followed by quantitative PCR in a 7300 Real-Time PCR System (Applied Biosystems, USA) using SYBR ${ }^{\circ}$ Premix Ex Taq $^{\text {Ta }}$ II (Takara Biotechnology). The primers used in these reactions are listed in Table 1. Levels of miR-21 were normalized to levels of U6, while levels of CSC marker mRNAs were normalized to levels of glyceraldehyde-3-phosphate dehydrogenase (GAPDH) mRNA. All results were calculated using the $2[-\Delta \Delta \mathrm{C}(\mathrm{T})]$ method. All experiments were performed in triplicates.

\section{Western blot analysis}

Total cell lysates were prepared from the negative control cell line and cell line stably transfected with miR-21, fractionated on SDS-PAGE and transferred to PVDF membranes (Millipore). After blocking the membranes in phosphate-buffered saline (PBS) containing $0.1 \%$

Table 1 Primers used for reverse transcription and amplification of genes related to liver cancer stem cells

\begin{tabular}{|c|c|}
\hline Gene & Primer sequence $\left(5^{\prime} \rightarrow 3^{\prime}\right)$ \\
\hline \multirow[t]{2}{*}{ miR-21 } & F: ACTCAGCTGG TAGCTTATCAGACTGATG \\
\hline & R: TGGTGTCGTGGAGTCG \\
\hline \multirow[t]{2}{*}{ U6 } & F: CTCGCTTCGGCAGCACA \\
\hline & R: AACGCTTCACGAATTTGCGT \\
\hline \multirow[t]{2}{*}{ CD13 } & F: TTCAACATCACGCTTATCCACC \\
\hline & R: AGTCGAACTCACTGACAATGAAG \\
\hline \multirow[t]{2}{*}{ Ep-CAM } & F: ATAACCTGCTCTGAGCGAGTG \\
\hline & R: TGCAGTCCGCAAACTITTACTA \\
\hline \multirow[t]{2}{*}{ CD90 } & F:ATGAAGGTCCTCTACTTATCCGC \\
\hline & R: GCACTGTGACGTTCTGGGA \\
\hline \multirow[t]{2}{*}{ OCT4 } & F: GTGTTCAGCCAAAAGACCATCT \\
\hline & R: GGCCTGCATGAGGGTTTCT \\
\hline \multirow[t]{2}{*}{ GAPDH } & F: CTGGGCTACACTGAGCACC \\
\hline & R: AAGTGGTCGTTGAGGGCAATG \\
\hline
\end{tabular}

$F$ forward, $R$ reverse
Tween 20 (PBST) and $5 \%$ non-fat dry milk for $2.5 \mathrm{~h}$ at room temperature, the PVDF membranes were probed at $4{ }^{\circ} \mathrm{C}$ overnight with rabbit antibodies (Abcam, UK) against CD13 (1:2,000), Ep-CAM (1:2,000), CD90 $(1: 1,000)$, and OCT4 $(1: 2,000)$. Then, membranes were washed with PBST three times and incubated for $2 \mathrm{~h}$ at room temperature with horseradish peroxidase (HRP)conjugated secondary antibody (1:2,000; Abcam). After washing the membranes three times with PBST, the proteins were detected using enhanced chemiluminescence (Thermo, USA) and quantified using ImageLab 5.0 (BioRad, USA). Protein levels were normalized to the amount of GAPDH detected on the same blot. Representative data from three independent experiments are shown.

\section{Spheroid formation assay}

To measure spheroid formation by stable cell lines, negative control cells and cells stably transfected with miR-21 were mixed with serum-free DMEM/F12 medium containing B27 supplement (1:50; Invitrogen), $20 \mathrm{ng} / \mathrm{mL}$ epidermal growth factor (Invitrogen), and $20 \mathrm{ng} / \mathrm{mL}$ basic fibroblast growth factor (Invitrogen) and plated in six-well dishes (2000 cells per well). Cells were incubated for 14 days, and the medium was replaced every 3 days. Spheroids were counted and photographed under a microscope (Nikon, Tokyo, Japan). All experiments were performed in triplicates.

\section{Migration and invasion assays}

Cell migration and invasion were analyzed using Transwell cell culture chambers with $8-\mu \mathrm{m}$ pores (Corning, USA). The upper chamber was coated with Matrigel (Corning) for invasion assays, but not for migration assays. Cells $\left(10^{5}\right)$ were added to the upper chamber without FBS, while lower chambers were immersed in medium containing $10 \% \mathrm{FBS}$ as a chemoattractant; the culture chambers were then incubated for $24 \mathrm{~h}$ at $37^{\circ} \mathrm{C}$. Cells were removed from the upper chamber using cotton swabs, and the filters were stained with methanol for $5 \mathrm{~min}$ at $37^{\circ} \mathrm{C}$, then fixed with Giemsa's solution (Solarbio, China) for $10 \mathrm{~min}$ at $37{ }^{\circ} \mathrm{C}$. Numbers of migrating and invasive cells were counted in five randomly selected fields on each filter. Representative data from three independent experiments are shown.

\section{Tumorigenicity in vivo}

Animal studies were performed according to the Guidelines of Intramural Animal Use and were approved by the Animal Ethics Committee of Guangxi Medical University. Negative control cells or cells stably transfected with miR-21 $\left(1 \times 10^{7}\right)$ were suspended in a 1:1 $(v / v)$ mixture of $100 \mu \mathrm{l}$ PBS and Matrigel (BD, USA) and injected subcutaneously into both sides of five male BALB/C 
nude mice aged 5-6 weeks (Laboratory Animal Center, Guangxi Medical University). Tumor length and width were examined every 3-5 days in a specific pathogenfree laboratory using a vernier caliper. At 34 days after injection, nude mice were given an intraperitoneal injection of chloral hydrate, and then killed by cervical dislocation. Tumors were weighed, and tumor volumes were calculated using the equation: volume $\left(\mathrm{mm}^{3}\right)$ $=\left(\right.$ length $\times$ width $\left.^{2}\right) / 2$.

\section{Statistical analysis}

Statistical analysis was performed using SPSS 19.0 (IBM, USA). Data were presented as mean \pm standard deviation, and inter-group differences were assessed for significance using Student's $t$ test. All statistics should be two-tailed, and the threshold of significance was defined to be $p<0.05$.

\section{Results}

\section{An HCC cell line stably overexpressing miR-21}

The analysis of PCR reactions on $1.0 \%$ agarose showed the desired 589-bp miR-21 amplicon, which was digested with BamHI and SalI for insertion into the retroviral vector. The expression construct pBABE-puro-pre-miR21 was transformed into E. coli DH5. Plasmid DNA was isolated from a panel of transformants and digested with BamHI/SalI to screen for the 589-bp insert. The resulting pBABE-puro-pre-miR-21 was used to create an MHCC-97H cell line stably overexpressing miR-21 (Fig. 1). RT-PCR analysis showed that miR-21 expression was $7.78 \pm 1.51$-fold higher in the miR-21-transfected cultures than in the negative control cultures $(p<0.05)$.

\section{miR-21 increased the expression of LCSC markers}

Cells stably overexpressing miR-21 contained approximately twofold more mRNA encoding four LCSC markers than in the negative control cells: for CD13, the difference was $2.07 \pm 0.10$-fold $(p=0.004)$; Ep-CAM, $2.23 \pm 0.13(p=0.006)$; CD90, $2.01 \pm 0.10(p=0.005)$; and OCT4, $1.97 \pm 0.12$ ( $p=0.008$; Fig. 2a). Expression of the four corresponding proteins was also significantly higher in miR-21-overexpressing cells $(p<0.05$; Fig. $2 b)$. These results indicate that miR-21 overexpression strengthened the LCSC phenotype.

\section{miR-21 increased clonogenicity}

Negative control cells and cells stably overexpressing miR-21 formed loose aggregates that eventually coalesced into compact, tight, rounded spheres that grew over the 14-day incubation. Sphere morphology was analyzed in detail using light microscopy, which showed that miR-21-overexpressing cells formed tighter, larger, more numerous, and more confluent spheres (Fig. 3). These results indicated that higher expression of LCSC

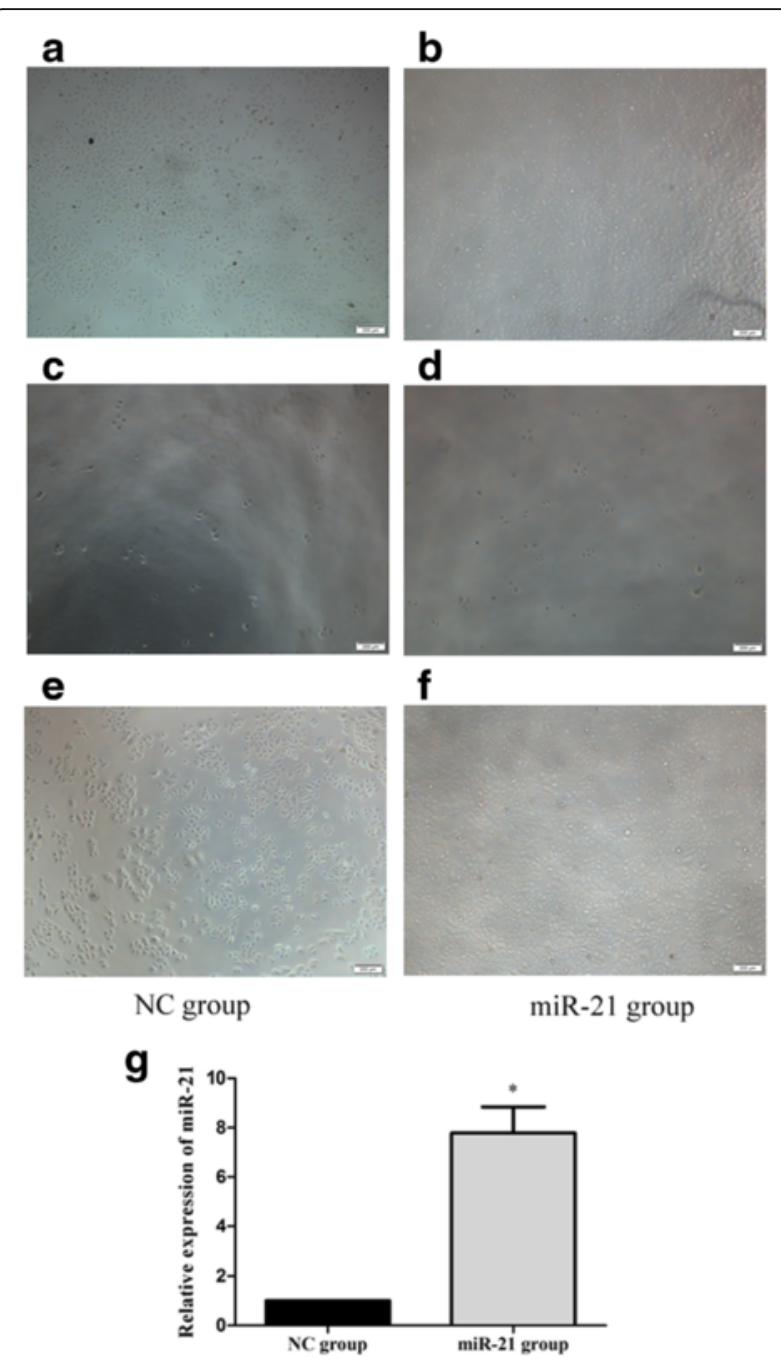

Fig. 1 An MHCC-97H cell line stably overexpressing miR-21 was selected and cultured in the presence of puromycin (magnification, $\times 200$ ). $\mathbf{a}, \mathbf{b}$ Negative control (NC) cultures and cultures stably transfected with miR21 were mock-transfected in the absence of retroviral particles. $\mathbf{c}, \mathbf{d}$ Transfected cells were grown for 2 weeks in DMEM containing $1 \mu \mathrm{g} / \mathrm{ml}$ puromycin without other antibiotics. e, $\mathbf{f}$ The two cell lines were cultured for 2 months in DMEM containing $500 \mathrm{ng} / \mathrm{ml}$ puromycin without other antibiotics. $\mathbf{g}$ Relative expression of miR-21 was determined by RT-PCR. ${ }^{*} p<0.05$, compared with NC

surface markers correlated with greater sphere-forming ability.

miR-21 promoted migration and invasion

In Transwell assays, miR-21-overexpressing cells showed greater migration and invasion ability than the negative control cells. The number of migrating cells measured in randomly selected fields of the Transwell culture insert was significantly higher with the miR-21-overexpressing cultures than the negative control cultures $(210.3 \pm 5.8$ vs. 104.8 $\pm 6.5, p<0.001$ ), and the relative number of cells that invaded through the extracellular matrix 


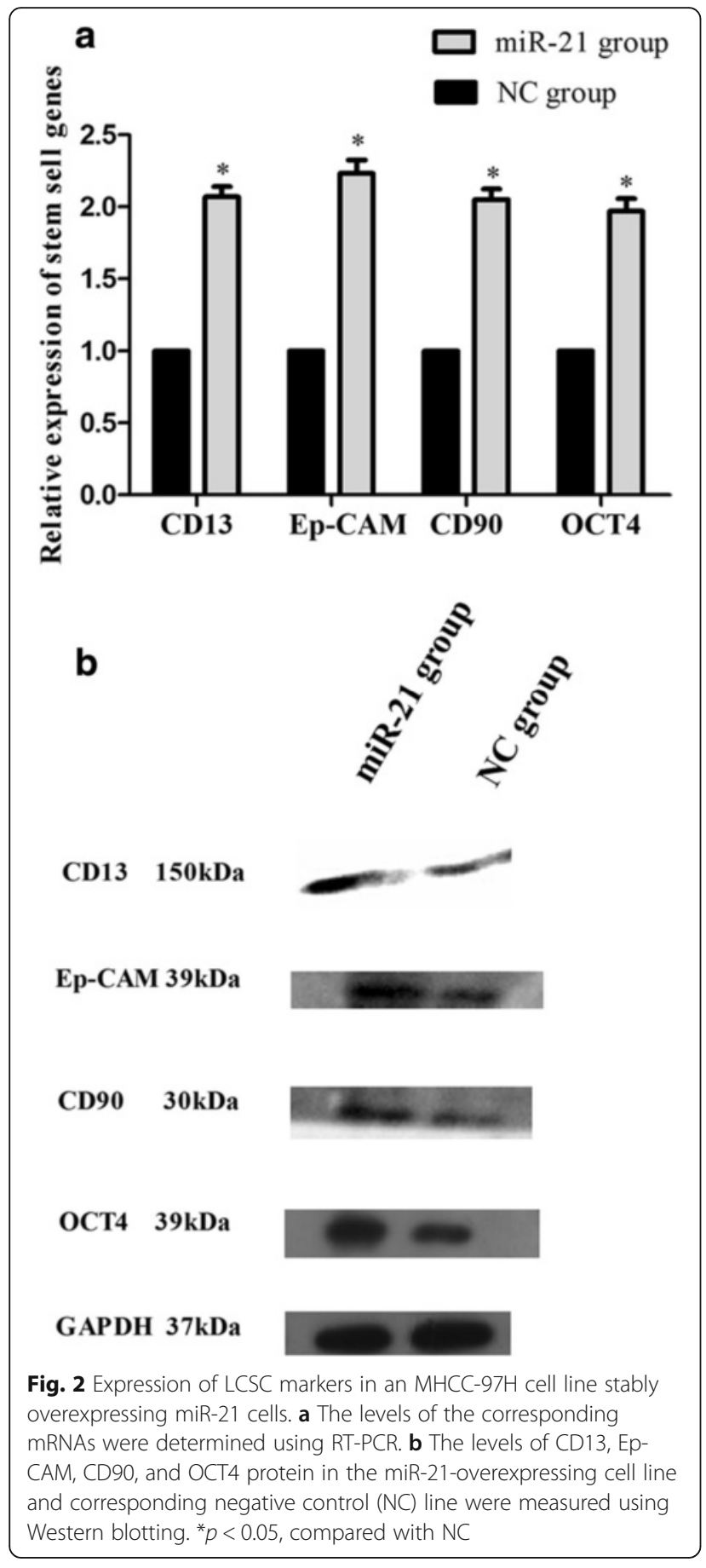

coating was significantly higher for the miR-21overexpressing cultures $(107.3 \pm 2.3)$ than for the negative control cultures $(56.7 \pm 2.5, p<0.001$; Fig. 4).

miR-21 accelerated tumor growth in BALB/C nude mice BALB/C nude mice were inoculated with negative control cells or cells stably transfected with miR-21, and tumors were allowed to grow. Tumors were visible after 5 days in both groups of mice, but tumors from cells

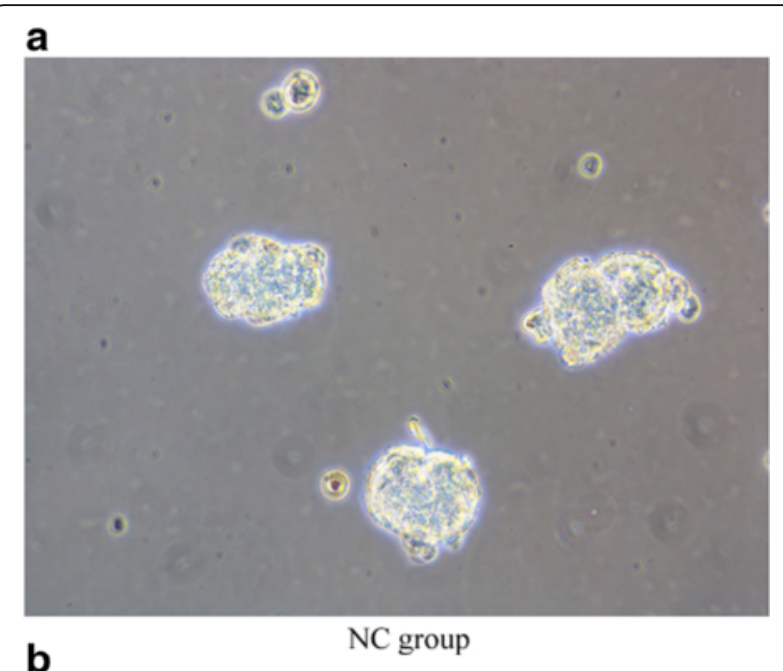

b

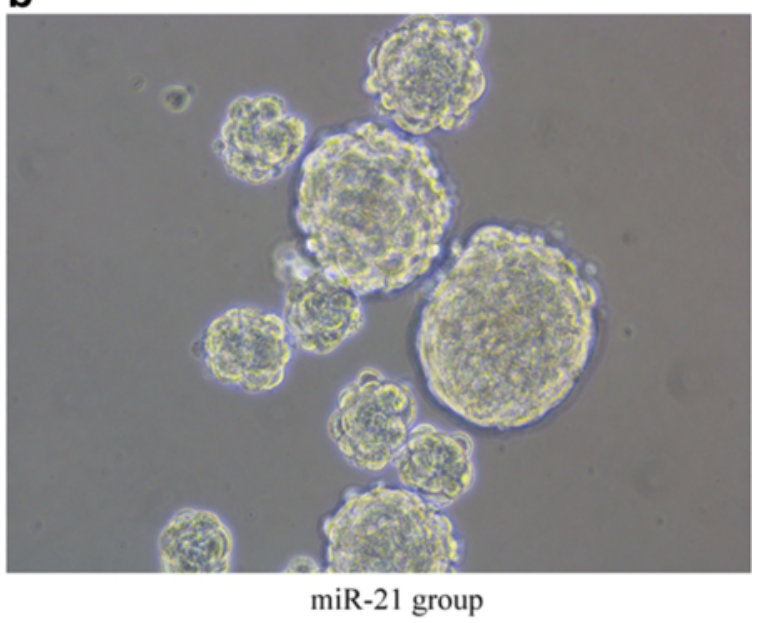

Fig. 3 Overexpression of miR-21 promotes spheroid formation. $\mathbf{a}, \mathbf{b}$ MHCC-97H cell line stably overexpressing miR-21 and the corresponding negative control (NC) cell line were induced to form spheroids for 14 days. The miR-21-overexpressing cell line formed larger, tighter, and more numerous spheroids

overexpressing miR-21 grew significantly faster (Fig. 5b). On day 28 after inoculation, two mice died, and postmortem dissection showed them to have pulmonary metastases. Mean tumor volume at the end of the 34-day observation period was $773.62 \pm 163.46 \mathrm{~mm}^{3}$ in the miR21 group and $502.79 \pm 33.94 \mathrm{~mm}^{3}$ in the negative control group ( $p=0.048$ ), while the corresponding mean weights were $0.422 \pm 0.019 \mathrm{~g}$ and $0.346 \pm 0.006 \mathrm{~g}(p=0.003$, Table 2 and Fig. 5c), respectively. Tumor pathology was verified by histopathology.

\section{Discussion}

LCSCs are thought to arise from hepatocyte dedifferentiation or transformation from hepatic progenitor cells, and many investigators believe that LCSCs generate and maintain $\mathrm{HCC}$ and drive postoperative recurrence $[15,32,33]$. This implies that inhibiting and 

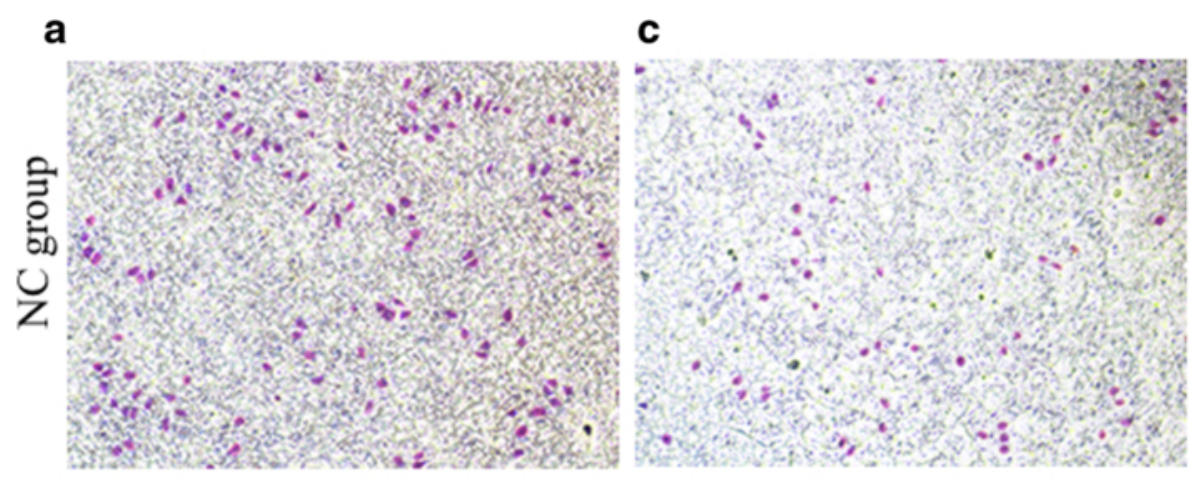

b
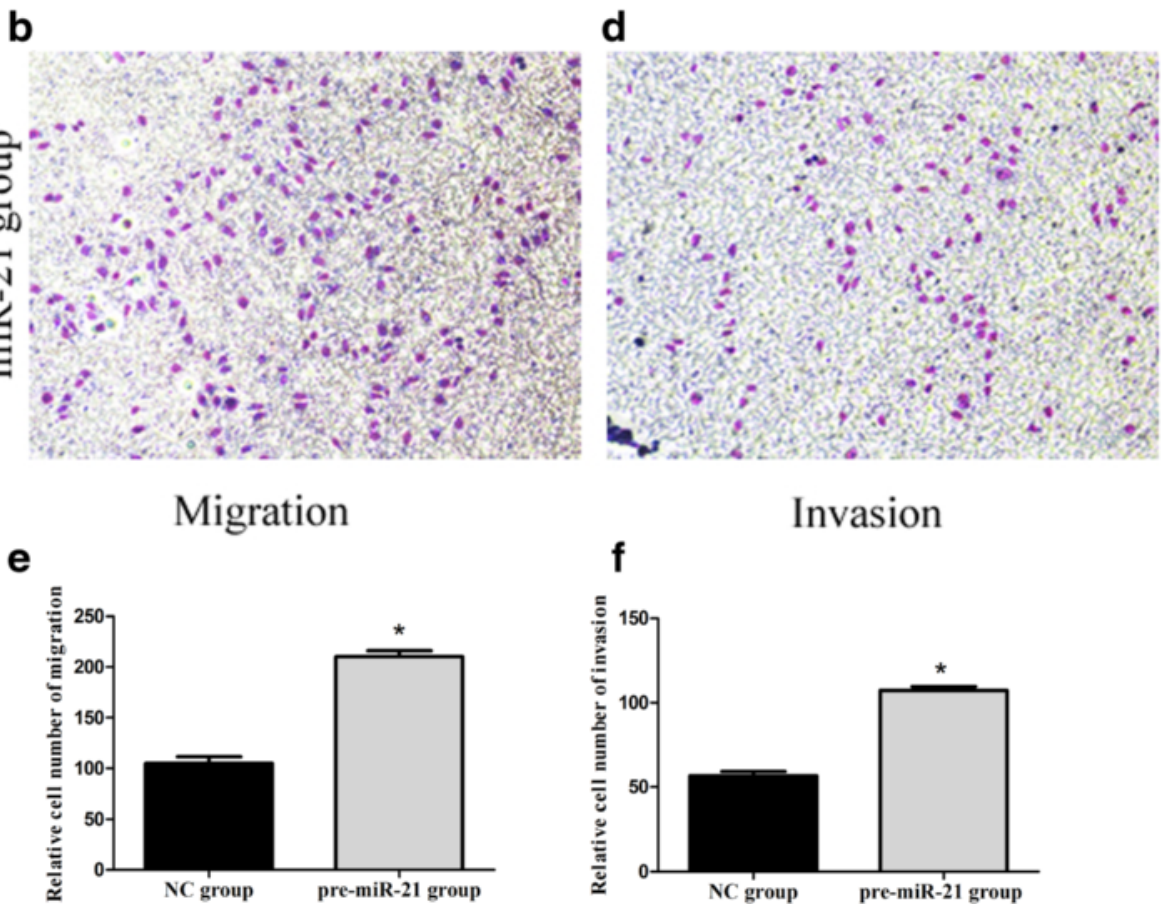

Fig. 4 Overexpression of miR-21 promotes cell migration and invasion. a-d Transwell migration and Matrigel invasion assays were carried out using MHCC-97H cells stably overexpressing miR-21 or the corresponding negative control (NC) cells. e, $\mathbf{f}$ Numbers of migrating and invading cells counted in five fields randomly selected on the Transwell culture insert. ${ }^{*} p<0.001$, compared with NC

eliminating LCSCs may be key to reducing recurrence $[34,35]$. Here, we confirm and extend previous work in isolated LCSCs by showing that overexpression of miR21 in the HCC cell line MHCC-97H directly affects numerous functional characteristics of LCSCs, providing mechanistic insight into the events that may drive HCC recurrence and suggesting a potential therapeutic target.

Ep-CAM and CD90 are widely regarded as LCSC markers, and higher expression of these markers has been linked to greater risk of recurrence and shorter survival time in HCC $[23,24]$. We found that miR-21 overexpression was associated with increases in expression of these markers and of the LCSC markers CD13 and OCT4. Previous work showed that miR-21 can promote tumor spread by upregulating the expression of phosphatase and tensin homolog (PTEN), programmed cell death 4 (PDCD4) protein, and reversion-inducing cysteine-rich protein with Kazal motifs (RECK) [22]. Future studies should aim to determine the full range of target genes affected by miR-21, since this may help clarify the complex literature on risk factors of HCC recurrence.

CD13, which helps pause LCSCs in G1/G0 phase of the cell cycle [25], has already proven a useful drug target: the combination of a CD13 inhibitor with the genotoxin fluorouracil (5-FU) led to significantly smaller tumor size than either drug on its own in a mouse xenograft tumor model [26]. CD13 is special among LCSC markers because its level changes during differentiation of LCSCs in culture [36]: upregulation of CD13 is associated with the epithelial-mesenchymal transition and with a reduction in apoptosis. It is also associated with the 

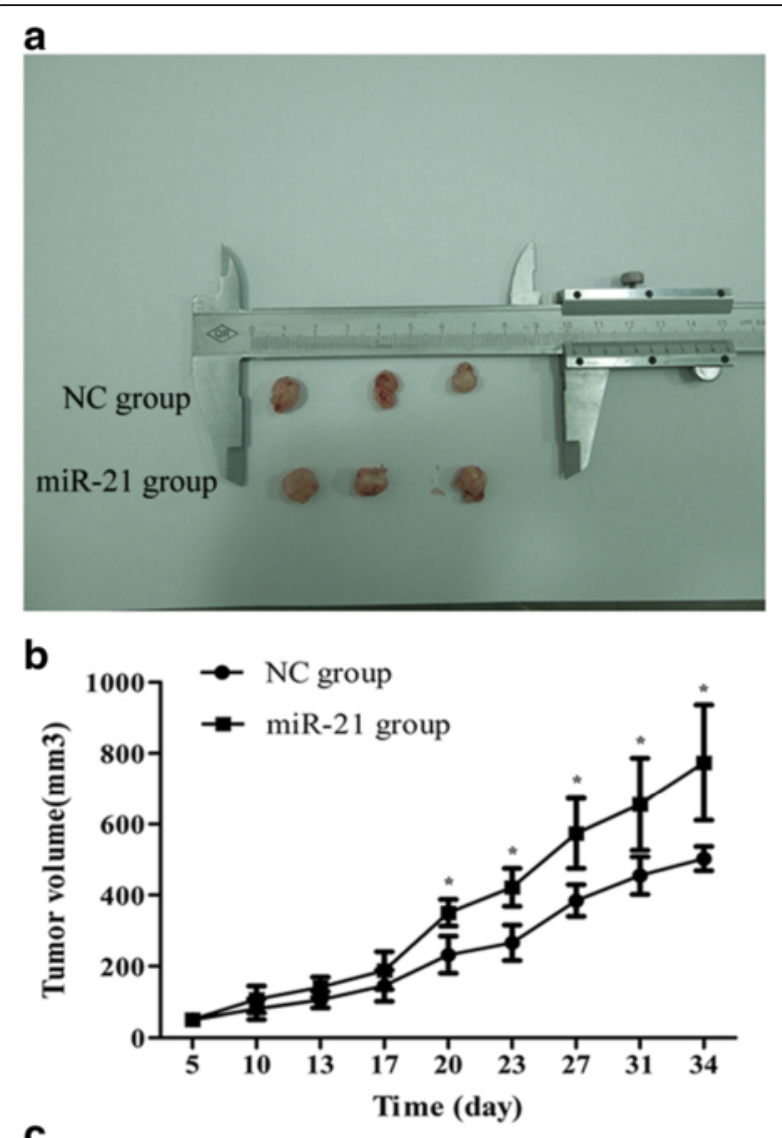

C

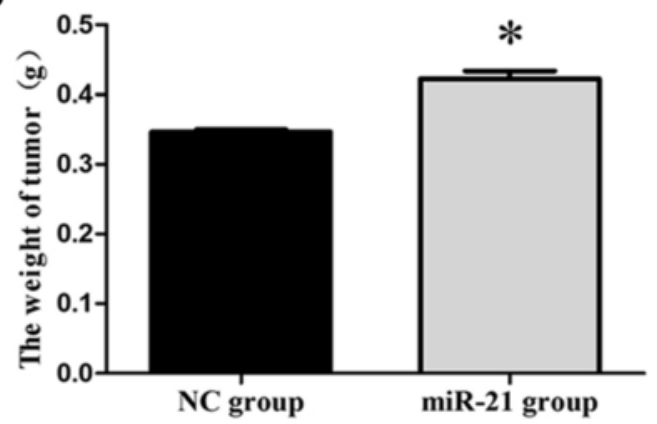

Fig. 5 Overexpression of miR-21 promotes the growth of subcutaneous xenograft tumors in nude mice. a Representative xenograft tumors grown for 34 days using MHCC-97H cells stably overexpressing miR-21 or the corresponding negative control (NC) cells. $\mathbf{b}$ The tumor volume and $\mathbf{c}$ tumor weight were compared between the two stable cell lines. ${ }^{*} p<0.05$, compared with NC
Table 2 Subcutaneous xenograft tumor weight at 34 days after tumor cell injection

\begin{tabular}{lll}
\hline Cell line & Weight, $g($ mean \pm SD $)$ & $P$ \\
\hline Negative control & $0.346 \pm 0.006$ & 0.003 \\
miR-21 & $0.422 \pm 0.019$ & \\
\hline
\end{tabular}

resistance of LCSCs to chemotherapy and more robust survival [37]. OCT4 plays a pivotal role in maintaining the multidirectional differentiation and self-renewal properties of embryonic stem cells [27-29]. OCT4 is highly expressed by cells highly enriched for CD90- and CD133-positive LCSCs, and its expression is tightly associated with chemotherapy resistance [38]. Coexpression of OCT4 and another "stem-ness" marker, Nanog, by $\mathrm{HCC}$ cells is associated with aggressive tumor behavior and worse clinical outcome [28]. OCT4 can promote CSC-like traits as well as the epithelial-mesenchymal transition in HCC cells; it exerts these effects by regulating the Stat3/Snail pathway [39]. Future work should examine whether OCT4 may be a reasonable therapeutic target for preventing HCC recurrence.

How miR-21 may promote the behavior of LCSCs, or of CSCs in general, remains unclear. Some mechanisms have been proposed [40]. One is that miR-21 acts within the tumor progenitor cells to modulate their selfrenewal. Another is that miR-21 in non-progenitor tissue triggers tumor cell differentiation, leading to CSC production. A third is that miR-21 in non-progenitor cells produces growth factors that benefit CSCs.

Our observation that miR-21 overexpression increases the ability of MHCC-97H cells to invade and metastasize echoes a report that transfecting SMMC-7721 cells with an miR-21 analog markedly enhanced their invasion and metastasis abilities. Indeed, inhibiting miR-21 in MHCC97H cells reduced these abilities [41]. Similarly, silencing trans-expressed miR-21 in isolated LCSCs reduced their migration and invasion [22].

Our observation that miR-21 overexpression leads to faster tumor growth in a nude mouse xenograft model is consistent with a report that inhibiting miR-21 in pancreatic CSCs substantially decreased the growth of pancreatic tumor xenografts [42]. In another study, colorectal cancer cells were stably transfected with miR21 plasmid and subcutaneously injected into female SCID mice [43]. At 6 weeks after injection, tumors were larger in mice injected with cells stably transfected with miR-21 than in mice injected with the corresponding empty vector. That work further showed that miR-21 overexpression can induce the appearance of colorectal CSCs.

\section{Conclusions}

The results of the present study suggest that miR-21 overexpression can upregulate CD13, Ep-CAM, CD90, and OCT4 expression. In addition, miR-21 strengthens LCSC characteristics, including spheroid formation, invasion, and migration. CSC marker expression may regulate the expression and activity of miR-21, thereby reinforcing the stem cell phenotype. 


\section{Abbreviations}

CSCs: Cancer stem cells; HCC: Hepatocellular carcinoma; LCSCs: Liver cancer stem cells; miR: microRNA; PDCD4: Programmed cell death 4;

PTEN: Phosphatase and tensin homolog; RECK: Reversion-inducing cysteinerich protein with Kazal motifs; RT-PCR: Quantitative real-time reverse transcription-PCR

\section{Acknowledgements}

The authors thank Armando Chapin Rodríguez, PhD, for his language editing, which substantially improved the quality of the manuscript.

\section{Funding}

This research was funded by the National Natural Science Foundation of China (grants 81260331 and 81360312), the Graduate Innovational Foundation of Guangxi (grant YCSZ2014108), and the National Science and Technology Major Project of the Ministry of Science and Technology of China (grant 2012ZX10002010001009).

\section{Availability of data and materials}

The scientists could be provided with the data on reasonable request from the corresponding author. And all authors consent for publication.

\section{Authors' contributions}

XBD and LLQ designed the study. JJH, YPP, and GZ performed the research $J J H, Y R R, Y H J$, and YFQ evaluated the data and performed the statistical analysis. JJH wrote the manuscript. All authors read and approved the final manuscript.

\section{Competing interests}

The authors declare that they have no competing interests.

\section{Consent for publication}

This manuscript does not contain any individual person's data and material. Please contact the authors for data requests.

\section{Ethics approval and consent to participate}

Animal studies were performed according to the Guidelines of Intramural Animal Use and were approved by the Animal Ethics Committee of Guangxi Medical University.

\section{Author details}

'Department of Hepatobiliary Surgery, Tumor Hospital of Guangxi Medical University, Nanning 530021, Guangxi Zhuang Autonomous Region, China. 2Department of General Surgery, The Second People's Hospital of Jing Men, Jingmen 448000, Hubei Province, China. ${ }^{3}$ Department of Thyroid and Breast Surgery, The Central Hospital of Wuhan, Wuhan 430041, Hubei Province, China. ${ }^{4}$ Department of Immunology, School of Preclinical Medicine, Biological Targeting Diagnosis and Therapy Research Center, Guangxi Medical University, Nanning 530021, Guangxi Zhuang Autonomous Region, China. ${ }^{5}$ Department of General Surgery, The First People's Hospital of Changde, Changde 415000, Hunan Province, China.

\section{Received: 27 February 2016 Accepted: 18 October 2016} Published online: 28 October 2016

\section{References}

1. Jemal A, Bray F, Center MM, Ferlay J, Ward E, Forman D. Global cancer statistics. CA Cancer J Clin. 2011;61:69-90.

2. Greten TF, Wang XW, Korangy F. Current concepts of immune based treatments for patients with HCC: from basic science to novel treatment approaches. Gut. 2015;64:842-8.

3. Moriguchi M, Takayama T, Higaki T, Kimura Y, Yamazaki S, Nakayama H, et al. Early cancer-related death after resection of hepatocellular carcinoma. Surgery. 2012;151:232-7.

4. Guo Z, Zhong JH, Jiang JH, Zhang J, Xiang BD, Li LQ. Comparison of survival of patients with BCLC stage A hepatocellular carcinoma after hepatic resection or transarterial chemoembolization: a propensity scorebased analysis. Ann Surg Oncol. 2014:21:3069-76.

5. Chiche L, Menahem B, Bazille C, Bouvier V, Plard L, Saguet V, et al. Recurrence of hepatocellular carcinoma in noncirrhotic liver after hepatectomy. World J Surg. 2013;37:2410-8.
6. Scadden DT. Cancer stem cells refined. Nat Immunol. 2004;5:701-3.

7. Yang XR, Xu Y, Yu B, Zhou J, Qiu SJ, Shi GM, et al. High expression levels of putative hepatic stem/progenitor cell biomarkers related to tumour angiogenesis and poor prognosis of hepatocellular carcinoma. Gut. 2010;59:953-62.

8. Wang Y, Yu Y, Tsuyada A, Ren X, Wu X, Stubblefield K, et al. Transforming growth factor-beta regulates the sphere-initiating stem cell-like feature in breast cancer through miRNA-181 and ATM. Oncogene. 2011;30:1470-80.

9. Gilbertson RJ, Graham TA. Cancer: resolving the stem-cell debate. Nature. 2012;488:462-3.

10. Li Y, Jiang F, Liu Q, Shen J, Wang X, Li Z, et al. Inhibition of the cancer stem cellslike properties by arsenic trioxide, involved in the attenuation of endogenous transforming growth factor beta signal. Toxicol Sci. 2015;143:156-64.

11. Casanova J. Stemness as a cell default state. EMBO Rep. 2012:13:396-7.

12. Hamburger AW, Salmon SE. Primary bioassay of human tumor stem cells. Science. 1977:197:461-3.

13. Yang ZF, Ngai P, Ho DW, Yu WC, Ng MN, Lau CK, et al. Identification of local and circulating cancer stem cells in human liver cancer. Hepatology. 2008; 47:919-28.

14. Mishra L, Banker T, Murray J, Byers S, Thenappan A, He AR, et al. Liver stem cells and hepatocellular carcinoma. Hepatology. 2009;49:318-29.

15. Yamashita T, Wang XW. Cancer stem cells in the development of liver cancer. J Clin Invest. 2013;123:1911-8.

16. Di Leva G, Garofalo M, Croce CM. MicroRNAs in cancer. Annu Rev Pathol. 2014:9:287-314.

17. Bao B, Li Y, Ahmad A, Azmi AS, Bao G, Ali S, et al. Targeting CSC-related miRNAs for cancer therapy by natural agents. Curr Drug Targets. 2012;13:1858-68.

18. Lerner RG, Petritsch C. A microRNA-operated switch of asymmetric-tosymmetric cancer stem cell divisions. Nat Cell Biol. 2014;16:212-4.

19. Meng F, Glaser SS, Francis H, DeMorrow S, Han Y, Passarini JD, et al. Functional analysis of microRNAs in human hepatocellular cancer stem cells. J Cell Mol Med. 2012:16:160-73.

20. Misawa A, Katayama R, Koike S, Tomida A, Watanabe T, Fujita N. AP-1Dependent miR-21 expression contributes to chemoresistance in cancer stem cell-like SP cells. Oncol Res. 2010;19:23-33.

21. Li R, Oian N, Tao K, You N, Wang X, Dou K. MicroRNAs involved in neoplastic transformation of liver cancer stem cells. J Exp Clin Cancer Res. 2010:29:169-79.

22. Zhou L, Yang ZX, Song WJ, Li QJ, Yang F, Wang DS, et al. MicroRNA-21 regulates the migration and invasion of a stem-like population in hepatocellular carcinoma. Int J Oncol. 2013;43:661-9.

23. Yamashita $T$, Honda M, Nakamoto $Y$, Baba M, Nio K, Hara Y, et al. Discrete nature of EpCAM+ and CD90+ cancer stem cells in human hepatocellular carcinoma. Hepatology. 2013;57:1484-97.

24. Guo Z, Li LQ, Jiang JH, Ou C, Zeng LX, Xiang BD. Cancer stem cell markers correlate with early recurrence and survival in hepatocellular carcinoma. World J Gastroenterol. 2014:20:2098-106.

25. Hirata H, Sugimachi K, Takahashi Y, Ueda M, Sakimura S, Uchi R, et al. Downregulation of PRRX1 confers cancer stem cell-like properties and predicts poor prognosis in hepatocellular carcinoma. Ann Surg Oncol. 2015; 22 Suppl 3:1402-9.

26. Christ $B$, Stock $P$, Dollinger MM. CD13: waving the flag for a novel cancer stem cell target. Hepatology. 2011;53:1388-90.

27. Cao L, Li C, Shen S, Yan Y, Ji W, Wang J, et al. OCT4 increases BIRC5 and CCND1 expression and promotes cancer progression in hepatocellular carcinoma. BMC Cancer. 2013;13:82-95.

28. Yin X, Li YW, Zhang BH, Ren ZG, Qiu SJ, Yi Y, et al. Coexpression of stemness factors Oct4 and Nanog predict liver resection. Ann Surg Oncol. 2012;19:2877-87.

29. Wang Z, Oron E, Nelson B, Razis S, Ivanova N. Distinct lineage specification roles for NANOG, OCT4, and SOX2 in human embryonic stem cells. Cell Stem Cel. 2012;10:440-54.

30. Qin S, Wang YT, Yang ZF, Chen QL, Guan WD, Wu SG, et al. Development and characterization of a stable cell line expressing respiratory syncytial virus non-structural protein NS1. Bing du xue bao. 2011:27:587-93.

31. King KW, Dybvig K. Transformation of Mycoplasma capricolum and examination of DNA restriction modification in M. capricolum and Mycoplasma mycoides subsp. mycoides. Plasmid. 1994;31:308-11.

32. Oishi N, Yamashita T, Kaneko S. Molecular biology of liver cancer stem cells. Liver Cancer. 2014;3:71-84

33. Pilz S, Schotta G. Emergence of cancer stem cells in hepatocellular carcinoma. EMBO J. 2015;34:425-6. 
34. Frank NY, Schatton T, Frank MH. The therapeutic promise of the cancer stem cell concept. J Clin Invest. 2010;120:41-50.

35. Rountree $C B$, Mishra L, Willenbring H. Stem cells in liver diseases and cancer: recent advances on the path to new therapies. Hepatology. 2012;55:298-306.

36. Yamada T, Abei M, Danjoh I, Shirota R, Yamashita T, Hyodo I, et al. Identification of a unique hepatocellular carcinoma line, Li-7, with CD13(+) cancer stem cells hierarchy and population change upon its differentiation during culture and effects of sorafenib. BMC Cancer. 2015;15:260.

37. Kim HM, Haraguchi N, Ishii H, Ohkuma M, Okano M, Mimori K, et al. Increased CD13 expression reduces reactive oxygen species, promoting survival of liver cancer stem cells via an epithelial-mesenchymal transitionlike phenomenon. Ann Surg Oncol. 2012;19 Suppl 3:S539-48.

38. Jia $Q$, Zhang $X$, Deng $T$, Gao J. Positive correlation of Oct4 and ABCG2 to chemotherapeutic resistance in CD90(+)CD133(+) liver cancer stem cells. Cell Reprogram. 2013;15(2):143-50.

39. Yin X, Zhang BH, Zheng SS, Gao DM, Qiu SJ, Wu WZ, Ren ZG. Coexpression of gene Oct4 and Nanog initiates stem cell characteristics in hepatocellular carcinoma and promotes epithelial-mesenchymal transition through activation of Stat3/Snail signaling. J Hematol Oncol. 2015;8:23.

40. Kang HY. MicroRNA-21 regulates stemness in cancer cells. Stem Cell Res Ther. 2013:4:110-1.

41. Bao L, Yan Y, Xu C, Ji W, Shen S, Xu G, et al. MicroRNA-21 suppresses PTEN and hSulf-1 expression and promotes hepatocellular carcinoma progression through AKT/ERK pathways. Cancer Lett. 2013;337:226-36.

42. Zhao Y, Zhao L, Ischenko I, Bao Q, Schwarz B, Niess H, et al. Antisense inhibition of microRNA-21 and microRNA-221 in tumor-initiating stem-like cells modulates tumorigenesis, metastasis, and chemotherapy resistance in pancreatic cancer. Target Oncol. 2015;10:535-48.

43. Yu Y, Kanwar SS, Patel BB, Oh PS, Nautiyal J, Sarkar FH, et al. MicroRNA-21 induces stemness by downregulating transforming growth factor beta receptor 2 (TGFbetaR2) in colon cancer cells. Carcinogenesis. 2012;33:68-76.

\section{Submit your next manuscript to BioMed Central and we will help you at every step:}

- We accept pre-submission inquiries

- Our selector tool helps you to find the most relevant journal

- We provide round the clock customer support

- Convenient online submission

- Thorough peer review

- Inclusion in PubMed and all major indexing services

- Maximum visibility for your research

Submit your manuscript at www.biomedcentral.com/submit

) Biomed Central 